\title{
Topikal Prostaglandin Analogları ve Hiperpigmentasyon
}

\section{Topical prostaglandin analogues and Hyperpigmentation}

\author{
Nilay Duman ${ }^{1}$, Reşat Duman ${ }^{2}$, Güliz Fatma Yavaş ${ }^{2}$ \\ 1 Afyon Kocatepe Üniversitesi, Tıp Fakültesi, Dermatoloji Ana Bilim Dalı, Afyonkarahisar, Türkiye. \\ 2 Afyon Kocatepe Üniversitesi, Tıp Fakültesi, Göz Hastalıkları Ana Bilim Dalı, Afyonkarahisar, Türkiye.
}

Öz

Topikal prostaglandin analogları glokom tedavisinde sık kullanılan ilaçlar arasında yer alır. Genel olarak güvenli ilaçlar olmalarına rağmen, konjonktival hiperemi, iris hiperpigmentasyonu, kirpiklerde uzama ve koyulaşma ve perioküler deride hiperpigmentasyon gibi lokal yan etkilere sahiptirler. Bu makalenin amacı, topikal prostaglandin analoglarına bağlı gelişen iris, kirpik ve perioküler deri hiperpigmentasyonuna dair mevcut literatür bilgisini derlemek, klinik özellikleri, olası etyopatogenetik mekanizmaları ve klinik sonuçları değerlendirmektir.

Anahtar Kelimeler: prostaglandin analoğu, hiperpigmentasyon, iris, kirpik, deri
ABSTRACT

Topical prostaglandin analogues are among commonly used glaucoma medications. These are considerably safe drugs, however they have some local adverse effects such as conjunctival hyperemia, iris hyperpigmentation, elongation and darkening of eyelashes, and periocular skin hyperpigmentation. The aim of the present article is to review available literature data on topical prostaglandin analogue-induced hyperpigmentation of iris, eyelash and periocular skin and to evaluate the clinical features, possible etiopathogenetic mechanisms, and clinical outcomes.

Keywords:

prostaglandin

analogue,

Corresponding Author: Nilay Duman

Address: Afyon Kocatepe Üniversitesi, Tıp Fakültesi, Dermatoloji

Ana Bilim Dalı, Afyonkarahisar, Türkiye.

Başvuru Tarihi/Received:

Kabul Tarihi/Accepted:

05-05-2015

29-05-2015 


\section{Giriş}

Topikal prostaglandin analogları (PGA'lar) primer açık açılı glokom tedavisinde kullanılan etkin ve güvenilir ilaçlardır ve günümüzde yaygın bir kullanıma sahiptir. Amerika'da glokom tedavisinde onayı olan bimatoprost $\quad$ (Lumigan $\left.{ }^{\circledR}\right), \quad$ latanoprost (Xalatan ${ }^{\circledR}$ ) ve travoprost (Travatan $\AA$ ) dışında Japonya'da kullanılan izopropil unoprostone (Rescula $\left.{ }^{\circledR}\right)$ ve klinik çalışmalarda yer alan tafluprost (Saflutan ${ }^{\circledR}$ ) olmak üzere 5 PGF $_{2 \alpha}$ analoğu glokom tedavisinde kullanılmaktadır. ${ }^{1}$ Travoprost ve latanoprost $\mathrm{PGF}_{2 \alpha}$ 'nin ester proilacıdır. Bimatoprost 17-fenil- PGF $_{2 \alpha}$ 'nın amid pro-ilacidır. Unoprostone $\mathrm{PGF}_{2 \alpha}$ 'nın pulmoner metabolitinin analoğudur, docosanoid olarak da adlandirılır. Tafluprost, PGF $_{2 \alpha}$ 'nın difloroprostaglandin derivesidir. ${ }^{1} \quad$ PGA'lar, aköz hümörün uveaskleral yol veya trabeküler ağ yoluyla dışa akışını artırarak göz içi basıncını düşürürler. ${ }^{1}$

Topikal PGA'lara bağlı görülen yan etkiler arasında; konjonktival hiperemi, kirpiklerde koyulaşma ve uzama, iris hiperpigmentasyonu, göz çevresinde hipertrikoz, iris kistleri, iridosiklit, kistoid maküler ödem, anterior üveit, süperfisyel punktat keratit, herpes simpleks keratiti reaktivasyonu, periorbital yağ kaybı, üst göz kapağ 1 sulkusunda derinleşme ve dermatoşalaziste artış yer alır. ${ }^{2-4}$ Son yıllarda, perioküler deride hiperpigmentasyon da topikal PGA'ların yan etkileri arasında bildirilmektedir. ${ }^{2,3} \mathrm{Bu}$ makaledeki amacimız PGA-hiperpigmentasyon ilişsisine dair mevcut literatür verilerini derlemek, klinik özellikleri, olası etyopatogenetik mekanizmaları ve klinik sonuçları değerlendirmektir.

\section{PGA-İris Hiperpigmentasyonu}

PGA ilişkili iris hiperpigmentasyonu birçok hayvan ve insan çalışmasında gösterilmiştir. $^{5-8} \quad$ Çalışmaların çoğu, latanoprostla yapılmıştır. ${ }^{6,8}$ İris hiperpigmentasyonu, travaprost ile latanoprosta benzer siklikta, bimatoprost ile daha az siklıkla, unoprostone ile ise en az s1klıkta bildirilmiştir. ${ }^{8}$ Farklı serilerde 1 y1llık latanoprost tedavisi sonras1 \%5-58.2 olguda, 3 y1ll1k latanaprost tedavisi sonrası \%8.5-70.4 olguda bildirilmiştir. ${ }^{8-11}$ Daha önceki serilerde 3-6 aylık bimatoprost tedavisi sonrası iriste hiperpigmentasyon gelişme sıklı̆g $1 \% 5$ 'den az olarak raporlanmasına rağmen, yakın zamanlı bir çalışmada Inoue ve ark. ${ }^{12} 52$ hastayı dahil ettikleri çalışmalarında 6 aylık bimatoprost tedavisi sonras1 \%50 hastada iriste hiperpigmentasyon bildirmişlerdir. Huang ve ark. $^{6} 3$ aylik travoprost ile tedavi edilen 73 gözü ve 42 kontrol gözü dahil ettikleri çalışmalarında hasta grubunun \%35.6'sında iriste hiperpigmentasyon geliştiğini göstermişlerdir.

PGA ilişkili iris hiperpigmentasyonunu belirleyen faktörlerden birisi tedavi süresidir. Tedavi süresi uzadıkça iriste hiperpigmentasyon riski artmaktadır. ${ }^{6}$ PGA ilişkili iris hiperpigmentasyonu için gerekli zaman 3-12 ay gibi durmaktadır, fakat nadiren tedavinin 1.ayında veya daha geç başlangıçlı hiperpigmentasyon olguları bildirilmiştir. $^{5}$ Latanoprost'un tetiklediği iris pigmentasyonu çalışma grubu sonuçlarına göre tedavinin 3, 6, 9,12 ve 15 . ayındaki iriste hiperpigmentasyon sıklığ sirasıla \%16.3, \%34.2, \%49.5, \%58.2 ve $\% 58.2$ olarak değişkenlik göstermektedir. ${ }^{7}$

PGA ilişkili iris hiperpigmentasyonunu belirleyen faktörlerden biri de bazal iris rengidir. Heterokromik kahverengi özellikle yeşil-kahve veya sarı-kahve irislerde uniform veya homokromik iris rengi olan hastalara kıyasla risk daha da artmaktadır. ${ }^{6,8}$ Üç yıllık latanoprost tedavisi sonras1 mavi/gri iriste koyulaşma oranı \%8.5 iken yeşil-kahve ve sar1-kahve irislerde bu oran $\% 69.2$ ve \%70.4'tür, uniform mavi iriste ise çok nadirdir. ${ }^{5,8}$ Tüm iris renkleri birlikte değerlendirildiğinde bu oran yaklaşık $\% 30$ 'dur. ${ }^{5}$ 
PGA ilişkili iris hiperpigmentasyonunun artmiş tirozinaz aktivitesine ve melanogeneze bağlı olduğu düşünülmektedir. ${ }^{5,6} \quad$ Prostaglandinlerin melanosit proliferasyonu üzerine etkisi olup olmadığı çeşitli in vitro çalışmalarda incelenmiş, ancak anlamlı artış izlenmemiştir. $^{5,8,13-16} \quad$ İris hiperpigmentasyonunun özellikle anterior yerleşimli olduğu, posterior iris epitelini etkilemediği, ayrıca inflamasyonla ilişkili olmadığ1 gösterilmiştir. ${ }^{8} \mathrm{Bu}$ olgularda histopatolojik inceleme ile iriste malign ya da prekanseröz bir değişiklik tespit edilmemiştir. ${ }^{8}$ Çeşitli çalışmalarla prostaglandinlerin hem tirozinaz gen transkripsiyonunu arttırarak hem de direkt tirozinaz enzim aktivitesini arttırarak melanogenezi arttırdığ 1 , bunun da muhtemelen prostanoid reseptör uyarımı yolu ile olduğu gösterilmiştir. ${ }^{2,8,17-20}$ Elektron mikroskopisi ile yapılan çalışmalarda immatür melanozom ya da matür melanin granüllerinin sayısında değişiklik olmadan var olan melanin granüllerinin boyutunun arttığı gösterilmiştir. ${ }^{8}$

PGA ilişkili iris hiperpigmentasyonu çoğunlukla tedavinin bitmesine rağmen düzelme göstermez veya çok yavaş gerileme gösterir. ${ }^{5,8}$ Bazı olgularda tedavinin sonlandırılması sonrası çok yavaş spontan renk açılması gösterilmiştir. ${ }^{5}$ Bunun mekanizması olarak melaninin intraselüler katabolizmas1 veya makrofajlar tarafindan fagositozu öne sürülmüştür. ${ }^{5}$

Resim 1' de, çift taraflı glokom nedeniyle topikal PGA kullanan, takibimizde olan 3 hastada gelişen iris pigment değişiklikleri izlenmektedir.

\section{PGA-Kirpik Hiperpigmentasyonu}

Kirpiklerde uzama ve koyulaşma PGA'ların iyi bilinen sık yan etkileri arasındadır. $^{2,8,21}$ PGA ilişkili kirpik değişiklikleri farklı serilerde \%0.7-76 arasında bildirilmiştir. $^{8,22-24}$ Johnstone ve ark. ${ }^{24}, 1997$ yılında, tek taraflı topikal latanoprost kullanan
43 hastada tedavi edilen tarafta kirpiklerde uzunluğun, kalınlığın ve pigmentasyonunun anlamlı olarak arttığını göstermiştir. Sonraki yıllarda tüm PGA tipleri ile ilişkili kirpik değişiklikleri bildirilmiştir. ${ }^{2}$ Sasaki ve ark. ${ }^{25}$ bir fare modelinde $\mathrm{PGF}_{2 \alpha}$ analoglarının kirpik folikülünü stimüle edici etkilerinin yanında foliküler melanogenezi arttırdığını da göstermişlerdir. $\mathrm{PGF}_{2 \alpha}$ reseptörlerinin kirpik melanositlerindeki tirozinaz aktivitesini ve melanogenez stimülatörü olarak rol oynayabilen endojen $\mathrm{PGE}_{2}$ üretimini arttırarak melanogenezi arttırdıklarını öne sürmüşlerdir. ${ }^{25}$
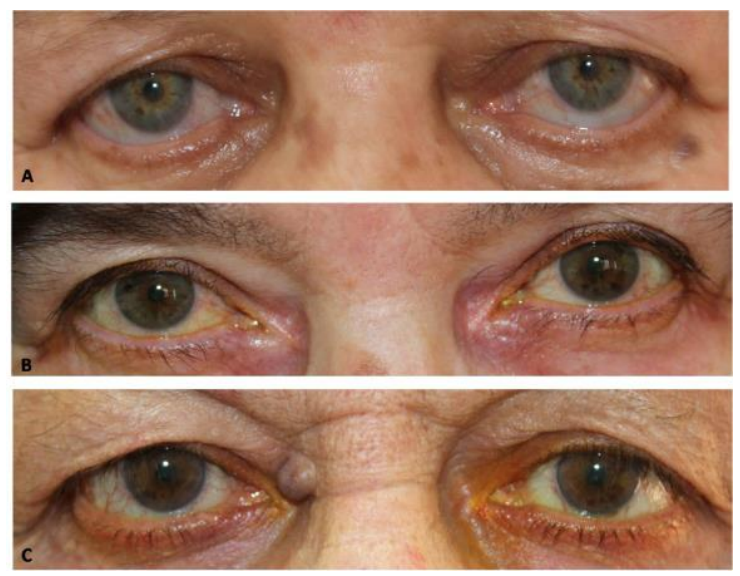

Resim 1A-C. Çift taraflı glokom nedeniyle topikal PGA kullanan 3 hastada iriste ortaya çıkan pigment değişiklikleri.

İristeki hiperpigmentasyondan farkl1 olarak, PGA ilişkili kirpik değişikliklerinin çoğunluğu tedavinin sonlandırılması ile düzelmektedir., ${ }^{3,26}$

Resim 2' de, çift taraflı veya tek taraflı glokom nedeniyle topikal PGA kullanan ve takibimizde olan hastalarda gelişen kirpik koyulaşması izlenmektedir.

\section{PGA-Perioküler Deride Hiperpigmentasyon}

Çeşitli yayınlarda topikal PGA kullanımına bağlı perioküler deride hiperpigmentasyon bildirilse de neden-sonuç ilişkisi henüz netlik kazanmamıştır. ${ }^{2}$ Anbar ve 
ark. $^{27} 18$ Gine domuzunu dahil etikleri klinikopatolojik çalışmalarında 4 haftalık topikal PGA (travoprost, bimatoprost ve latanoprost) tedavisinin perioküler deride anlamlı hiperpigmentasyona neden olduğunu göstermişlerdir. Üç tedavi ajanı arasında fark saptamamışlardır. Ayrıca çalışmalarında prostaglandinlere ek olarak darband UVB'nin uygulanması hiperpigmentasyonu daha da arttırmıştır, bunun sebeplerinden biri olarak UVB'nin in situ prostaglandin salınımını arttırması öne sürülmüştür. ${ }^{27}$
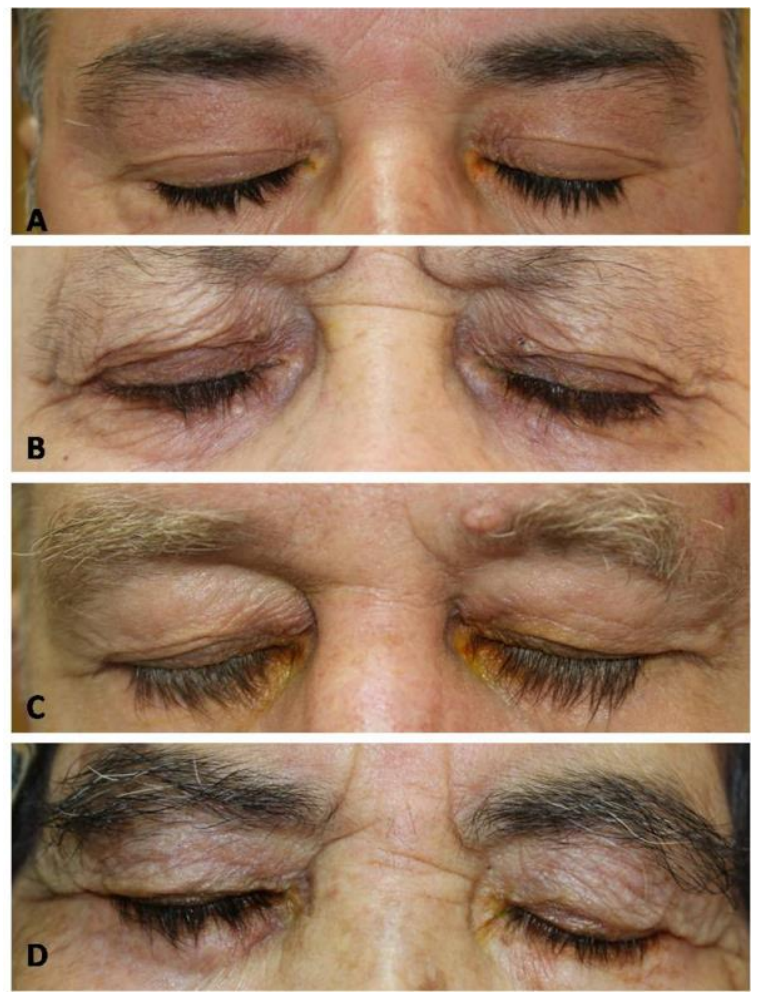

Resim 2A-D. Çift taraflı glokom nedeniyle topikal PGA kullanan hastalarda her iki gözde kirpiklerde uzama ve koyuşma (A-C) ve tek taraflı glokom nedeniyle topikal PGA kullanan hastada tedavi edilen tarafta daha belirgin kirpiklerde uzama ve koyulaşma (D).

Perioküler deride hiperpigmentasyon, tüm PGA'lar ile bildirilmiştir. ${ }^{3} \quad$ Farklı çalışmalarda latanoprost için \%0-5.9, travoprost için \%2.9-15.4, bimatoprost için \%1.6-25.9 arasında bildirilmiştir. ${ }^{3}$ Üç aydan uzun süredir topikal PGA (travoprost, tafluprost, bimatoprost, veya unoprostone) kullanan 250 hastayı içeren bir çalışmada hastaların \%4'ünde deride hiperpigmentasyon bildirilmiştir ve bu artışın ilaç tipi, yaş, cinsiyet, uygulanan göz ve intraoküler basınç ile ilişkisiz olduğu gösterilmiştir. ${ }^{3}$

Çalışma sonuçları arasındaki farklılığı belirleyen faktörlerden birisi tedavi süreleridir. Tedavi süresi uzadıçca deride hiperpigmentasyon riski artmaktadır. Üç aydan kısa tedavi süresi için perioküler hiperpigmentasyon \%1.5-2.9 iken 3 aydan uzun tedavi kullanan hastalarda \%0-25.9' dur. $^{3}$ Çalışmalarda kullanılan tanısal tekniklerin (slit lamp veya fotoğrafik değerlendirme) farkl1lık göstermesi sonuçların farklı olmasına neden olabilen bir diğer faktördür. ${ }^{3}$

$$
\text { PGA'ya bağlı perioküler }
$$

hiperpigmentasyonun mekanizması tam olarak bilinmemektedir. İris hiperpigmentasyonuna benzer olarak PGA'ların melanogenezi prostanoid reseptörler aracilığıyla arttırarak perioküler deride hiperpigmentasyona sebep olabileceği düşünülmektedir. ${ }^{2,28}$ Ancak, iris hiperpigmentasyonundan farklı olarak derideki hiperpigmentasyonda, esas olarak melanin granül boyutunun değil, melanin granüllerinin sayısının arttığı gösterilmiştir. ${ }^{29-31}$ Bazı yazarlar PGA ilişkili deri hiperpigmentasyonunun perioküler inflamasyona ikincil gelişebileceğini düşünse de bu çok kabul görmemiştir. ${ }^{2}$ Bimatoprost tedavisi kullanan 2 hastanın göz kapağ biyopsilerinin 1 şı ve elektron mikroskopisi ile incelendiği bir çalışmada, bimatoprost'un tetiklediği perioküler hiperpigmentasyonun melanositlerdeki artmış melanogeneze bağlı olduğu, melanosit proliferasyonu veya inflamasyon ile ilişkili olmadığı gösterilmiştir. ${ }^{31}$

PGA ilişkili perioküler deri hiperpigmentasyonu tedaviye başlandıktan 3 hafta-3 y1l sonra gelişebilmektedir. ${ }^{2,32,33}$ PGA ilişkili iris hiperpigmentasyonu çoğunlukla kalıcı iken deri hiperpigmentasyonu 
çoğunlukla ilaç kesilince gerilemektedir, tam geçme süresi tedavi kesiminden sonra 3-12 ay arasında değişmektedir. ${ }^{2}$

PGA ilişkili deri hiperpigmentasyonu tedavinin sonlandırılması ile gerilerken, iris hiperpigmentasyonunun gerilememesinin nedeni olarak deride dermal melanositlerin melanin granüllerini bazal keratinositlere aktarmas1 ve epidermal döngü ile pigmentin kayb1 ancak iris stromal melanositlerin melanini patolojik koşullar dışında bırakmaması öne sürülmüştür. ${ }^{2,28}$ Buna paralel olarak Wand ve ark. ${ }^{32}$ epidermiste bazal tabakadan-stratum korneuma geçiş zamanı ortalama 5 hafta, stratum korneumun dökülmesi de ortalama 2 hafta sürdüğü için PGA ilişkili deri hiperpigmentasyonunun geçebilmesi için tedavinin sonlandırılmasından sonra en az 7 hafta geçmesi gerektiğini belirtmişlerdir. ${ }^{32}$

Resim 3'de çift taraflı glokom nedeniyle topikal PGA kullanan ve takibimizde olan hastalarda gelişen perioküler hiperpigmentasyon, Resim 4'te tek taraflı glokom nedeniyle topikal PGA kullanan hastalarımızda tedavi edilen tarafta daha belirgin olan perioküler hiperpigmentasyon izlenmektedir.

\section{Sonuç}

\begin{tabular}{lll}
\multicolumn{2}{c}{ Topikal PGA kullanımı iriste, } \\
kirpiklerde ve perioküler
\end{tabular} hiperpigmentasyona neden olabilir. $\mathrm{Bu}$, temel olarak artmış melanogeneze ve tirozinaz aktivitesine bağlı gelişir. PGA ilişkili iris hiperpigmentasyonu tedavi kesimi ile gerilemezken, derideki ve kirpiklerdeki hiperpigmentasyon geriler. $\mathrm{Bu}$ tedavileri kullanacak hastalar olası yan etkiler ve klinik sonuçlar açısından bilgilendirilmelidir.
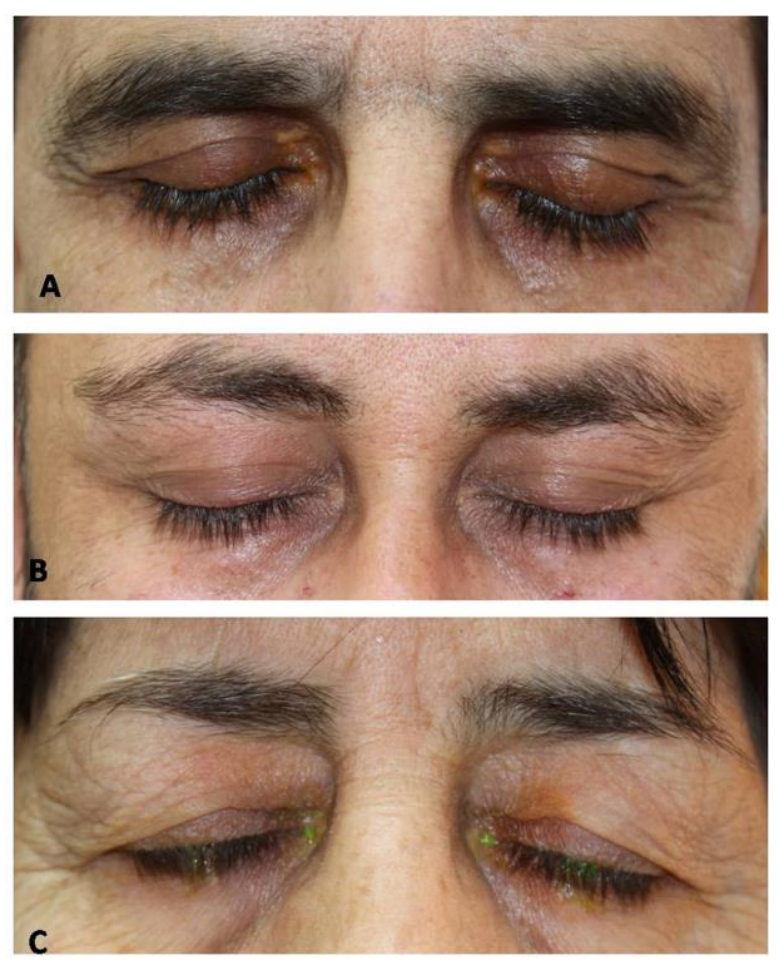

Resim 3A-C. Çift taraflı glokom nedeniyle topikal PGA kullanan hastalarda her iki perioküler deride hiperpigmentasyon.
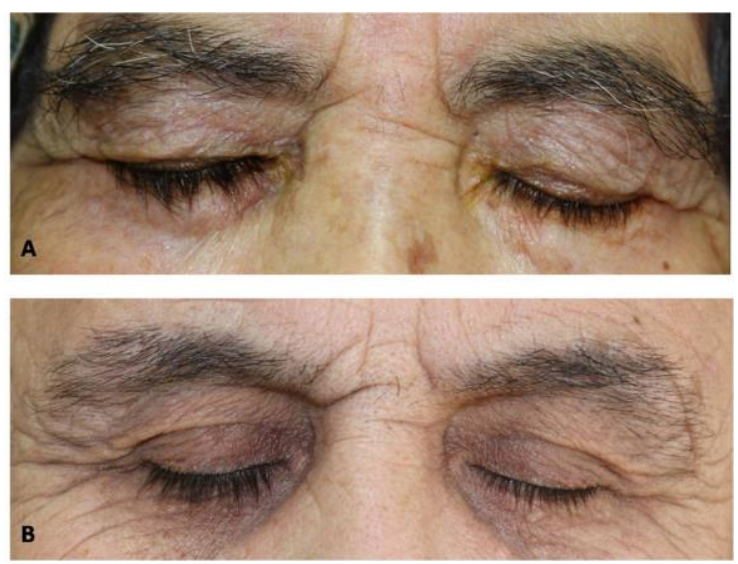

Resim 4A, B. Tek taraflı glokom nedeniyle topikal PGA kullanan hastalarda tedavi edilen tarafta daha belirgin kirpiklerde uzama, koyulaşma ve perioküler hiperpigmentasyon.

\section{Referanslar}

1. Toris CB, Gabelt BT, Kaufman PL. Update on the mechanism of action of topical prostaglandins for intraocular pressure reduction. Surv Ophthalmol 2008; 53(Suppl 1): 107120.

2. Alm A, Grierson I, Shields MB. Side effects associated with prostaglandin analog therapy. Surv Ophthalmol 2008; 53(Suppl 1): 93-105.

3. Inoue K, Shiokawa M, Higa R, Sugahara M, Soga T, Wakakura M, Tomita G. Adverse periocular reactions to five 
types of prostaglandin analogs. Eye (Lond) 2012; 26(11): 14651472.

4. Ung T, Currie ZI. Periocular changes following longterm administration of latanoprost $0.005 \%$. Ophthal Plast Reconstr Surg 2012; 28(2): e42-44.

5. Stjernschantz JW, Albert DM, Hu DN, Drago F, Wistrand PJ. Mechanism and clinical significance of prostaglandin-induced iris pigmentation. Surv Ophthalmol 2002; 47(Suppl 1): 162-175.

6. Huang P, Zhong Z, Wu L, Liu WJ. Increased iridial pigmentation in Chinese eyes after use of travoprost $0.004 \%$. Glaucoma 2009; 18(2): 153-156.

7. Latanoprost-Induced Iris Pigmentation Study Group. Incidence of a latanoprost-induced increase in iris pigmentation in Japanese eyes. Jpn J Ophthalmol 2006; 50(2): 96-99.

8. Cracknell KP, Grierson I. Prostaglandin analogues in the anterior eye: their pressure lowering action and side effects. Exp Eye Res 2009; 88(4): 786-791.

9. Wistrand P, Stjernschantz J, Olsson K. The incidence and time course of latanoprost-induced iridial pigmentation as a function of eye color. Surv Ophthalmol 1997; 41(Suppl 2): 129138.

10. Camras CB. Comparison of latanoprost and timolol in patients with ocular hypertension and glaucoma: a six-month masked, multicenter trial in the United States. The United States Latanoprost Study Group. Ophthalmology 1996; 103(1): 138147.

11. Chiba T, Kashiwagi K, Kogure S, Abe K, Shibuya T, Furuichi M, lijima H, Tsukahara S.Iridial pigmentation induced by latanoprost ophthalmic solution in Japanese glaucoma patients. J Glaucoma 2001; 10(5): 406-410.

12. Inoue $K$, Shiokawa $M$, Sugahara $M$, Higa $R$, Wakakura M, Tomita G. Iris and periocular adverse reactions to bimatoprost in Japanese patients with glaucoma or ocular hypertension. Clin Ophthalmol 2012; 6: 111-116.

13. Hu DN, Stjernschantz J, McCormick SA. Effect of prostaglandins $\mathrm{A}(2), \mathrm{E}(1), \mathrm{F}(2$ alpha)and latanoprost on cultured human iridal melanocytes. Exp Eye Res 2000; 70(1): 113-120

14. Loeffler KU, Sahm M, Spitznas M Short-time application of latanoprost does not stimulate melanogenesis in bovine ocular melanin-containing cells in vitro. Ophthalmic Res 2001; 33(2): 102-106.

15. Friedmann PS, Wren FE, Matthews JNS. Ultraviolet stimulated melanogenesis by human melanocytes is augmented by di-acyl glycerol but not TPA. J Cell Physiol 1990; 142(2): 334-341.

16. Tomita Y, Maeda K, Tagami H. Melanocytestimulating properties of arachidonic acid and metabolites: possible role in postinflammatory pigmentation. Pigment Cell Res 1992; 5(5 Pt 2): 357-361

17. Lindsey JD, Jones HL, Hewitt EG, Angert M, Weinreb RN. Induction of tyrosinase gene transcription in human iris organ cultures exposed to latanoprost. Arch Ophthalmol 2001; 119(6): 853-860.

18. Stjernschantz J, Ocklind A, Wentzel P, Lake S, Hu DN. Latanoprost induced

increase of tyrosinase transcription in iridial melanocytes. Acta Ophthalmol Scand 2000; 78(6): 618-22.
19. Park HY, Gilchrest BA: Protein kinase C: biochemical characteristics and role in melanocyte biology. J Dermatol Sci 1993; 6(3): 185-193.

20. Park HY, Perez JM, Laursen R, Hara M, Gilchrest BA. Protein kinase C-beta activates tyrosinase by phosphorylating serine residues in its cytoplasmic domain. J Biol Chem 1999; 274(23): 16470-16478.

21. Paul LJ, Cohen PR, Kurzrock R. Eyelash trichomegaly: review of congenital, acquired, and drugassociated etiologies for elongation of the eyelashes. Int $\mathrm{J}$ Dermatol 2012; 51(6): 631-646.

22. Chiba T, Kashiwagi K, Ishijima K, Furuichi M, Kogure S, Abe K, Chiba N, Tsukahara S. A prospective study of iridial pigmentation and eyelash changes due to ophthalmic treatment with latanoprost. Jpn J Ophthalmol 2004; 48(2): 141147.

23. Inoue $\mathrm{K}$, Wakakura $\mathrm{M}$, Inoue $\mathrm{J}$, Matsuo $\mathrm{H}$, Hara $\mathrm{T}$, Tomita G. Adverse reaction after use of latanoprost in Japanese glaucoma patients. Nihon Ganka Gakkai Zasshi 2006; 110(8): 581-587.

24. Johnstone MA. Hypertrichosis and increased pigmentation of eyelashes and adjacent hair in the region of the ipsilateral eyelids of patients treated with tek taraflı topical latanopros. Am J Ophthalmol 1997; 124(4): 544-547.

25. Sasaki S, Hozumi Y, Kondo S. Influence of prostaglandin F2 alpha and its analogues on hair regrowth and follicular melanogenesis in a murine model. Exp Dermatol 2005; 14(5): 323-328

26. O'Toole L, Cahill M, O'Brien C. Eyelid hypertrichosis associated with latanoprost is reversible. Eur $\mathrm{J}$ Ophthalmol 2001; 11(4): 377-379.

27. Anbar TS, El-Ammawi TS, Barakat M, Fawzy A. Skin pigmentation after NB-UVB and three analogues of prostaglandin $\mathrm{F}$ (2alpha) in guinea pigs: a comparative study. J Eur Acad Dermatol Venereol 2010; 24(1): 28-31.

28. Grierson I, Jonsson M, Cracknell K. Latanoprost and pigmentation Jpn J Ophthalmol 2004; 48(6): 602-612.

29. Cracknell KP, Grierson I, Hogg P, Appleton P, Pfeiffer N. Latanoprost induced iris darkening: a morphometric study of human peripheral iridectomies. Exp Eye Res 2003; 77(6): 721-730.

30. Cracknell KP, Grierson I, Hogg P. Morphometric effects of long-term exposure to latanoprost. Ophthalmology 2007; 114(5): 938-948.

31. Kapur R, Osmanovic S, Toyran S, Edward DP. Bimatoprost-induced periocular skin hyperpigmentation: histopathological study. Arch Ophthalmol 2005; 123(11): 15411546 .

32. Wand M, Ritch R, Isbey EK Jr, Zimmerman TJ. Latanoprost and periocular skin color changes. Arch Ophthalmol 2001; 119(4): 614-615.

33. Herndon LW, Robert D Williams, Wand M, Asrani S.Increased periocular pigmentation with ocular hypotensive lipid use in African Americans. Am J Ophthalmol 2003; 135(5): 713-715. 